\title{
"ESTADO DO CAMPO" DA PESQUISA EM POLÍTICAS PÚBLICAS NO BRASIL*
}

\author{
Celina Souza
}

\section{Introdução}

Não existem dúvidas sobre o crescimento da área de políticas públicas na pesquisa acadêmica que se realiza atualmente no Brasil. Várias áreas do conhecimento, e não só a ciência política, vêm realizando pesquisas sobre o que o governo faz, ou deixa de fazer. Portanto, a academia, juntamente com órgãos governamentais e centros de pesquisa, estes últimos com tradição mais antiga na área, têm ampliado sua presença nos estudos e pesquisas sobre políticas públicas. Vários departamentos de ciência política também têm contribuído para o crescimento e a legitimação da área com criação de cadeiras em políticas públicas. Essa é uma das boas

* Comunicação apresentada no Encontro Nacional da Associação Brasileira de Ciência Política realizado em junho de 2002, em Niterói, na mesa redonda Perspectivas da Agenda de Pesquisa em Políticas Públicas. notícias que sinalizam a relevância da área em nossas diversas instituições acadêmicas.

Outra boa notícia devemos à Anpocs, com o balanço feito por Marcus Melo (1999) sobre a trajetória e os temas recorrentes na área de políticas públicas em anos recentes. Chegou-se à conclusão de que, apesar de a área ainda apresentar problemas do ponto de vista acadêmico, ela tem crescido em qualidade e em volume de produção, apontando para a maturidade de sua produção científica.

\section{Problemas e possibilidades de avanços}

Para discutir o "estado do campo" e as perspectivas da agenda de pesquisa em políticas públicas no Brasil, optei por começar pelo mapeamento de seus principais problemas. Baseio esse mapeamento na minha própria experiência e não 
em um estudo sistemático sobre o tema. Levantar os problemas não significa, evidentemente, que eles sejam de difícil solução. Ao contrário, muitos decorrem justamente do crescimento da disciplina entre nós.

O primeiro a ser superado, também identificado por Melo (1999), parece ser o da escassa acumulação do conhecimento na área. Na sua argumentação, Melo sustenta, com pertinência, que o que se busca não é uma acumulação linear do conhecimento, mas a construção de um programa normal de pesquisa, no sentido kuhniano, envolvendo a comunidade de pesquisadores. Pode-se também acrescentar a isso que o diálogo entre pesquisadores da área, ou melhor, o conhecimento e o debate sobre o que os pesquisadores estão produzindo, ainda é escasso. No entanto, creio que esse é um dos problemas cuja solução mais tem avançado, com a constituição de fóruns específicos sobre políticas públicas em espaços acadêmicos como a Anpocs e a ABCP, assim como pelo advento da informatização de periódicos nacionais (via o portal scielo) e internacionais (via o portal de periódicos da Capes). Esses fóruns e instrumentos permitem-nos conhecer melhor e mais rapidamente a produção de nossos pares, embora não exista um periódico específico que abrigue exclusivamente a produção da área. ${ }^{1}$ No entanto, as disciplinas que contam com uma certa unidade de métodos e com contornos mais nítidos em relação ao seu objeto têm mais possibilidades de gerar conhecimento cumulativo do que um campo como o da política pública, que carrega uma tradição metodológica, de temas e de teorias muito difusa. Ou seja, se, por um lado, existe pouca acumulação do conhecimento e escasso diálogo entre trabalhos dos pesquisadores da área, por outro, temos hoje muito mais meios e instrumentos para superar tais limitações.

O segundo problema, também apontado por Melo (1999), decorre de uma razão oposta à primeira, ou seja, existe abundância de estudos setoriais, em especial estudos de caso, dotando a área de uma diversificação de objetos empíricos que se expandem horizontalmente, sem um fortalecimento vertical da produção, especificamente o analítico (p. 91). Aliado ao excesso de produção de estudos setoriais, pode-se acrescentar ainda que, sendo a área de política pública subdividida em várias subáreas, esses estudos focalizam, em geral, aspectos determinados de uma política pública. Isto porque a disciplina abarca, no mínimo, análises sobre a identificação do problema que vai ou não se transformar em uma política, ou seja, a definição da agenda (agenda setting), a formulação da própria política, sua legitimação, gestão, implementação e avaliação. Assim, a existência de muitos estudos setoriais, que transitam por várias áreas do conhecimento, e não apenas pela ciência política, aliados às subáreas nas quais a análise de políticas públicas se desdobra, é da essência mesma da disciplina. Em síntese, o problema do crescimento horizontal excessivo versus a falta de fortalecimento vertical decorre do crescimento da própria disciplina no Brasil, pois ela assumiu uma formação que mais gira em torno de áreas temáticas do que de grupos de pesquisa.

O terceiro problema, que também Melo (1999) vislumbrou, diz respeito à proximidade da área com os órgãos governamentais, que tanto podem gerar trabalhos normativos e prescritivos, como a possibilidade de esses órgãos pautarem a nossa agenda de pesquisa. Esse problema existe não apenas em relação aos órgãos do governo, que financiam muitas de nossas pesquisas, mas também aos organismos multilaterais. A perspectiva nessa aspecto é a de fortalecimento da área dentro dos organismos de financiamento de pesquisa puramente acadêmica, tanto nacionais como estrangeiros.

Mas não só a proximidade desses órgãos pautam nossas pesquisas. Há também uma grande tentação de enveredarmo-nos por novos temas que suscitam apenas um interesse particular, sem que se pese uma perspectiva propriamente acadêmica, gerando, em alguns momentos, uma proliferação de estudos sobre o mesmo tema, que, como pouco dialogam entre si, prejudicam a acumulação do conhecimento. Por exemplo, com a redemocratização e o novo desenho da gestão das políticas sociais, proliferaram trabalhos, especialmente dissertações e teses, sobre as políticas públicas adotadas por governos locais, 
em especial os administrados pelo PT, quando conhecemos ainda muito pouco sobre como outros partidos políticos governam as cidades e implementam suas políticas públicas. Também têm sido abundantes os estudos sobre as formas de participação popular na gestão das políticas públicas e, ultimamente, sobre os conselhos comunitários criados, em princípio, para decidir sobre as políticas sociais. Ou seja, a escolha dos temas de pesquisa parece indicar um excesso de trabalhos acerca de temas específicos, enquanto se observa uma grande lacuna sobre temas importantes que ainda não aportaram em nossa agenda de pesquisa. Temas, por exemplo, como o da burocracia - segmento que implementa as políticas públicas - ainda contam com muitos poucos trabalhos vis-à-vis sua importância para o melhor conhecimento do que acontece quando a política é implementada. ${ }^{2}$ A superação desse problema talvez resida em um papel mais direto dos orientadores de pesquisa. A chave para avançarmos na questão dos temas de pesquisa, do conhecimento cumulativo e do formação de grupos de pesquisa pode estar mais nos orientadores do que nos mestrandos e doutorandos.

Ainda no que se refere ao foco de análise e assumindo a existência de uma grande concentração de trabalhos sobre a implementação das políticas públicas, precisamos superar o que a literatura chama de primeira geração de estudos nessa área, excessivamente concentrada nos fracassos, pouco preocupada com as questões políticas e fortemente assentada no pressuposto de que a formulação e a implementação de políticas públicas são processos exclusivamente racionais e lineares, desvinculados dos processos políticos. Esse tipo de análise ainda é muito influenciado pela tentativa de se separar o mundo do governo e da administração pública do mundo da política. Precisamos, então, avançar para a chamada segunda geração, que deve seguir na direção do desenvolvimento de tipologias analíticas, e concentrar esforços no sentido de identificar as variáveis que causam impactos sobre os resultados das políticas públicas. Essa trajetória vai da dicotomia de analisar sucessos ou fracassos das políticas públicas para um estágio onde se enfatiza o o melhor entendimento dos resultados. Creio que talvez estejamos entrando nesse estágio, mas precisamos avançar ainda mais, especialmente por meio de uma maior utilização da literatura específica sobre políticas públicas, em particular o segmento que se concentra na construção de tipologias.

Outro caminho que, creio, precisamos adentrar é o que se chama de análise bottom-up. Sua importância cresceu a partir dos anos de 1980 com a pesquisa realizada por Michael Lipsky (1980), que chamou a atenção para o fato de que os modelos de análise em políticas públicas eram excessivamente concentrados em atores (decisores) que elaboram uma política. Sem desprezar o uso de modelos top-down de análise, as pesquisas passaram a usar, também, análises bottom-up, que partem de três premissas: a) analisar a política pública a partir da ação dos seus implementadores, em oposição à excessiva concentração de estudos acerca de governos, decisores e atores que se encontram na esfera "central"; b) concentrar a análise na natureza do problema que a política pública busca responder; e c) descrever e analisar as redes de implementação. Modelos de análise bottom-up podem ser passíveis de crítica quanto à sua capacidade explicativa, mas, por não ignorarem a complexidade de uma política, precisam ser mais testados entre nós. Além disso, ao assumir a complexidade da política pública como algo a ser explicado, em especial a sua implementação, esse tipo de pesquisa tem dificuldades para conviver com a busca recorrente do mainstream das Ciências Sociais, qual seja, o de se fixar na simplicidade analítica e na elegância dos modelos explicativos.

\section{Teorias e tipologias}

Do ponto de vista teórico-metodológico, embora tenha havido avanços, creio que a área ainda apresenta um uso excessivo de narrativas pouco pautadas por modelos ou tipologias de políticas públicas, por teorias próximas do objeto de análise e que mantêm uma leveza metodológica exagerada. No entanto, já existem trabalhos que superam essas limitações. Além disso, com a acei- 
tação, na ciência política brasileira, da literatura neo-institucionalista, as possibilidades para que a área adquira maior rigor teórico-metodológico são maiores hoje do que em um passado recente.

Apesar do sucesso da literatura neo-institucionalista na academia brasileira, é preciso, contudo, ter muito cuidado com o seu uso. Dois dos seus ramos têm encontrado bastante apoio na comunidade: o da escolha racional e o do institucionalismo histórico. Claro que as fronteiras entre os diversos ramos do neo-institucionalismo nem sempre são claras e, sendo um aporte teórico ainda em processo de construção, é preciso saber, com mais firmeza, quando e como utilizá-lo. Até porque não podemos esquecer que a análise de política pública é, por definição, estudar o governo em ação, motivo pela qual nem sempre os pressupostos neo-institucionalistas se adaptam à sua análise. Ou seja, a articulação entre a análise da política pública e o papel das instituições, ou das regras do jogo, nem sempre é muito clara. Estudos baseados, por exemplo, no modelo do ciclo da política pública, em especial a definição de agenda (agenda setting), podem ser muito promissores para a compreensão da política pública, assim como modelos construídos com base na teoria das elites, como o das redes sociais. ${ }^{3}$ No entanto, há ausência de trabalhos que testem, entre nós, tipologias sobre políticas públicas desenvolvidas nos chamados países centrais, como, por exemplo, a desenvolvida por Lowi (1964, 1972). ${ }^{4}$ Não só essas tipologias foram muito pouco exploradas entre nós, como também não foram testadas em um universo diverso daquele onde foram formuladas. Ademais, ainda temos pouca clareza sobre quem formula as nossas políticas públicas e como elas são implementadas. ${ }^{5}$ O teste de um dos principais argumentos de Lowi, de que a política pública faz a política, também tem sido pouco aplicado entre nós, em especial do ponto de vista comparativo entre diferentes políticas.

\section{Comentários finais}

Gostaria de concluir este texto destacando uma última questão e discutindo uma lacuna que, creio, precisa ser preenchida para que possamos avançar na pesquisa em políticas públicas.

O problema diz respeito ao uso de rótulos que muitos estudos continuam dando às políticas públicas no Brasil, em especial às políticas sociais. Ainda muito influenciadas por uma visão de que o Brasil é, por excelência o território de fenômenos como clientelismo, paroquialismo, patrimonialismo e outros tantos "ismos", todos pouco lisonjeiros, muitas análises continuam sendo norteadas por eles. No entanto, e até onde tenho conhecimento, não temos respostas empírica e teoricamente embasadas de como esses rótulos, se de fato existem, se manifestam e quais suas conseqüências para as políticas públicas. Um trabalho importante como o de Edson Nunes (1997), por exemplo, sobre as quatro gramáticas que convivem na burocracia pública brasileira, não teve continuidade entre nós. Há realmente uma convivência dessas gramáticas? Algumas predominam em determinadas políticas públicas, enquanto outras formas de intermediação de interesses (tecnocráticas, insulamento burocrático, redes sociais) guiam outras políticas, como as mais voltadas para a área econômica? Precisamos parar de repetir o que muitos brasilianistas defendem sobre a forma pela qual o Estado brasileiro e suas políticas públicas funcionam, para investigarmos a fundo tais fenômenos. Acredito que devemos urgentemente incorporar na nossa agenda de pesquisa o papel desses fenômenos nas políticas públicas.

Pesquisas comparativas a respeito da performance de diferentes políticas públicas, seguindo a trilha que vem sendo aberta pelos trabalhos de Marta Arretche (2000), é uma lacuna que precisa ser superada. Paralelamente, é necessário uma compreensão mais abrangente e comparativa sobre as políticas desenvolvidas na esfera dos Estados. Muitos países federativos já têm uma longa tradição em pesquisas nessa área, no sentido de entender por que os Estados dão respostas diversas às questões sociais. Já temos estudos importantes sobre políticas públicas nacionais e sobre políticas locais, mas sabemos ainda muito pouco sobre questões cruciais na esfera estadual. Não sabemos ainda, por exem- 
plo, por que existem diferenças tão marcantes nas políticas formuladas e/ou implementadas pelos governos estaduais. Este é um tema de pesquisa importante no Brasil, considerando que uma das marcas do federalismo brasileiro é a concentração de poder legislativo sobre políticas públicas na esfera federal, inclusive em áreas consideradas de competência concorrente entre as esferas federal e estadual.

Apesar dos problemas e das lacunas na agenda de pesquisa em políticas públicas, rapidamente alinhavados aqui, creio que temos nos saído relativamente bem se pensarmos o quanto essa área é ainda recente no Brasil.

\section{NOTAS}

1 Ver http://www.scielo.br e http://www.periodicos.capes.gov.br.

2 O trabalho coordenado por Asmeron e Reis (1996), que analisou as conseqüências das mudanças de regime político sobre as burocracias de países recém-democratizados, é um bom ponto de partida para a pesquisa sobre as transformações na burocracia brasileira.

3 Sobre redes sociais, ver Eduardo Marques (2000).

4 Entre as tipologias bastante testadas em estudos empíricos sobre políticas públicas de outros países, mas ainda pouco utilizadas entre nós, encontram-se a do "ciclo da política pública", do modelo garbage can, de Cohen, March e Olsen (1972), da "coalizão de defesa" (advocacy coalition), de Sabatier e JenkinsSmith (1993), do multiple-streams, de Kingdon (1984), que toma como ponto de partida o modelo garbage can, e o do punctuated equilibrium, de Baumgartner e Jones (1993). A pesquisa realizada por Fucks (1998) testa este último modelo, analisando a inserção da temática ambiental no Rio de Janeiro. Para uma discussão da aplicação de tipologias na análise de políticas públicas tomando como referência a teoria da escolha racional, ver Ostrom (1999). Análises de políticas sociais a partir da teoria do institucionalismo histórico vêm sendo produzidas por diversos autores, em especial Theda Skocpol. Já a literatura internacional sobre redes sociais é ampla e diversificada. Para uma revisão dessa literatura, ver Marques (2000).

5 Para uma discussão da aplicabilidade dessas tipologias às políticas públicas brasileiras, ver Frey (2000).

\section{BIBLIOGRAFIA}

ARRETCHE, Marta T. S. (2000), Estado federativo e politicas sociais: determinantes da descentralização. Rio de Janeiro/São Paulo, Revan/Fapesp.

ASMERON, Haile \& REIS, Elisa. (1996), Democratization and bureaucratic neutrality. Londres/Nova York, Macmillan/St. Martin's Press.

BAUGARTNER, Frank \& JONES, Bryan. (1993), Agendas and instability in American politics. Chicago, University of Chicago Press.

COHEN, Michael; MARCH, James \& OLSEN, Johan. (1972), "A garbage can model of organizational choice". Administrative Science Quarterley, 17: 1-25.

FREY, Klaus. (2000), "Políticas públicas: um debate conceitual e reflexões referentes à prática da análise de políticas públicas no Brasil”. Planejamento e Políticas Públicas, 21: 211-259.

FUCKS, Mario. (1998), "Arenas de ação e debate públicos: conflitos ambientais e a emergência do meio ambiente enquanto problema social no Rio de Janeiro". Dados, 41 (1): 230-245.

KINGDON, John. (1984), Agendas, alternatives, and public policies. Boston, Little Brown.

LIPSKY, Michael. (1980), Street level bureaucracy. Nova York, Russel Sage.

LOWI, Theodor. (1964), "American business, public policy, case studies and political theory". World Politics, 16: 677-715.

. (1972), "Four systems of policy, politics, and choice". Public Administration Review, 32: 298-310.

MARQUES, Eduardo C. (2000), Estado e redes sociais: permeabilidade e coesão nas politicas urbanas no Rio de Janeiro. São Paulo/Rio de Janeiro, Fapesp/Revan. 
MELO, Marcus André. (1999), "Estado, governo e políticas públicas", in Sergio Miceli (org.), O que ler na ciência social brasileira (1970-1995): Ciência Politica, São Paulo/Brasília, Sumaré/Capes.

NUNES, Edson. (1997), A gramática politica do Brasil, Brasília/Rio de Janeiro, ENAP/ Jorge Zahar.

OSTROM, Elinor. (1999), "An assessment of the institutional analysis and development framework", in Paul Sabatier (ed.), Theories of the policy process, Boulder, Westview Press.

SABATIER, Paul \& JENKINS-SMITH, Hank. (1993), Policy change and learning: the advocacy coalition approach. Boulder, Westview Press. 


\section{"ESTADO DO CAMPO" DA PESQUISA EM POLÍTICAS PÚ- BLICAS NO BRASIL}

\author{
Celina Souza
}

\section{Palavras-chave}

Política pública; Pesquisa; Brasil.

Este trabalho discute o "estado do campo" da área de políticas públicas, analisando as lacunas e as possibilidades da produção acadêmica no Brasil. A autora analisa as condições favoráveis para o amadurecimento teórico e metodológico das pesquisas em políticas públicas, apesar das lacunas temáticas e dos problemas teóricos e metodológicos que requerem o cuidado e a atenção dos pesquisadores.

\section{"STATE OF THE FIELD" ON "ÉTAT DES LIEUX" DE LA RE- THE PUBLIC POLICIES RE- CHERCHE EN POLITIQUES SEARCH IN BRAZIL PUBLIQUES AU BRÉSIL}

Celina Souza

\section{Key words}

Public policy; Research; Brazil.

The article discusses the "state of the field" on public policies research in Brazil, analyzing its academic performance coupled with its limits, gaps, and possibilities. The article argues that, on the one hand, there are favorable conditions for improving the theoretical and methodological problems faced by public policies research; on the other hand, there are still issues and some theoretical and methodological gaps claiming for more careful attention from researchers.
Celina Souza

\author{
Mots-clés \\ Politiques publiques; Recherche; \\ Brésil.
}

Ce travail discute l'état des lieux du domaine des politiques publiques, en analysant les lacunes et les possibilités de la production académique au Brésil. L'auteur analyse les conditions favorables à la mise au point théorique et méthodologique des recherches en politiques publiques, malgré les lacunes thématiques et des problèmes théoriques et méthodologiques qui requièrent l'attention et la vigilance des chercheurs. 